\title{
A THREE-LEVEL DISPOSAL SITE SELECTION CRITERIA SYSTEM FOR TOXIC AND HAZARDOUS WASTES IN THE PHILIPPINES
}

\author{
Reynaldo Perez-Ramos ${ }^{1}$ \\ ${ }^{1}$ Associate Professor, College of Engineering and Technology, Romblon State University \\ rsu.rpramos@gmail.com
}

\begin{abstract}
One of the perennial problems in managing toxic and hazardous wastes (THWs) generated from industrial activities is the final storage and disposal area for such kind of wastes. Due to inadequate land surface disposal facility (LSDF) in the country, waste generators are continually practicing the WHIFFY (we-hide-it-freely-for years) approach; consequently becoming a threat to human health and the environment. Proper site selection for land surface disposal facility requires a consultative process, taking into consideration the various factors that affect the overall siting process towards an effective identification of land to be developed into acceptable and environmentally-safe land surface disposal structures. This paper attempts to establish a threelevel site selection system through a participatory approach; and this is validated using survey questionnaire and secondary data. The establishment of a three-level site selection system facilitates the initial disposal siting process which leads to the development of technically, socially, environmentally, and politically acceptable disposal facilities for THWs in the Philippines. This paper also recommends basic guidelines to further support the site selection process with the application of computer-based spatial decision support systems such as Geographic Information System (GIS) as part of the land suitability assessment analysis.
\end{abstract}

Keywords: Toxic And Hazardous Wastes, Disposal Siting, Land Surface Facility, Site Selection, Geographic Information System.

\section{INTRODUCTION}

\subsection{Legal Basis in the TWHs Management in the}

\section{Philippines}

A number of laws and regulations have already been passed and currently enforce in managing THWs from industrial operations. These are as follows: Republic Act 6969 - Toxic Substances and Hazardous and Nuclear Waste Control Act of 1990; Republic Act 8749, Republic Act 9003 - Ecological Solid Waste Management Act of 2001; Environmental Impact Statement (EIS) System of 1978; Presidential Decree 984 - Pollution Control Decree of 1976; and Philippine Nuclear Research Institute (PNRI) Administrative Order No.01, s. 1990.

RA 6969 specifically regulates the generation, transport and disposal of THWs from industries, businesses and medical institutions. As defined by RA 6969, THWs are "substances which present short and long-term environmental hazards, without any safe commercial, industrial, agricultural and or economic usage; and by-products, process residues, spent reaction media, contaminated plant items or equipment from manufacturing operations, and consumer discards that present unreasonable risk or injury to health and the environment."

The primary sources of THWs are the semi-conductor and electronics industry, the electroplating industry and power plants. Secondary sources include hospital and medical facilities, testing laboratories, universities and research centers which give additional burdens in the overall THWs management. Due to the limited capacity for recycling and treatment of generated THWs in the country, industries handling waste acid, waste alkaline, waste oils, and sludge containing heavy metals are experiencing difficulty in managing it properly (Ex Corporation and Kokusai, 2001).

Table 1 shows the 2014 data of THWs sources and composition based on the registration of generators by region in the country (DENR-EMB, 2015). The 2014 data indicate that NCR has the highest share $(30.9 \%)$ of the number of registered THWs generators, followed by Region $3(15.3 \%)$ and Region 4A (14.8\%). There is a significant increase of generators in Region 3 compared to 1996 data of 4.6\% share; while NCR dramatically decreased its generation from $1996(47.2 \%)$ compared to $1.1 \%$ in 2014 . Surprisingly, Region 5 has the highest share in the THWs generation with $93.9 \%$, and $3.4 \%$ share in registered generators in 2014. The increase in registration and generation of THWs could be triggered by the strict compliance of RA 6969 and the economic and industrial development in the various regions.

In terms of type of THWs generation and composition (Table 2), Alkali wastes shared the highest percentage share of generation $(90.81 \%)$, followed by waste with inorganic chemicals (4.55\%), and miscellaneous wastes $(1.80 \%)$. Specifically, Region 5 (Bicol) generated the highest volume of THWs with $93.9 \%$ share of the total generation of 17.7 million tons of THWs from the 15 regions. This was followed by Region 7 (Central Visayas) with 2.6\% share, while Region 4A (Southern Tagalog) with $1.5 \%$ share, and NCR (Metro Manila) with $1.1 \%$ share. In particular, Region 4B (MIMAROPA) generated only 65.17 tons per year of mostly organic wastes. 
Table 1: THWs Generators in the Philippines by Region, 2014

\begin{tabular}{|c|c|c|c|c|c|c|}
\hline Region & No of Firms & No of Hospital & Total & \% Share & $\begin{array}{c}\text { THWs Generated } \\
\text { (ton/year) }\end{array}$ & \% Share \\
\hline NCR & 4158 & 2474 & 6632 & 30.9 & $187,607.56$ & 1.1 \\
\hline CAR & 259 & 73 & 332 & 1.5 & -* & 0.0 \\
\hline CARAGA & 342 & 91 & 433 & 2.0 & $38,777.00$ & 0.2 \\
\hline Region 1 & 950 & 126 & 1076 & 5.0 & $1,467.93$ & 0.0 \\
\hline Region 2 & 370 & 130 & 500 & 2.3 & 51.61 & 0.0 \\
\hline Region 3 & 3015 & 263 & 3278 & 15.3 & $-*$ & $\mathbf{0 . 0}$ \\
\hline Region 4A & 2931 & 239 & 3170 & 14.8 & $273,669.50$ & 1.5 \\
\hline Region 4B & 271 & 85 & 356 & 1.7 & 65.17 & $\mathbf{0 . 0}$ \\
\hline Region 5 & 644 & 86 & 730 & 3.4 & $16,639,462.88$ & 93.9 \\
\hline Region 6 & 771 & 210 & 981 & 4.6 & $1,299.29$ & 0.0 \\
\hline Region 7 & 1096 & 53 & 1149 & 5.4 & $451,877.11$ & 2.6 \\
\hline Region 8 & 415 & 115 & 530 & 2.5 & 508.64 & 0.0 \\
\hline Region 9 & 204 & 70 & 274 & 1.3 & 688.46 & 0.0 \\
\hline Region 10 & 336 & 85 & 421 & 2.0 & $-*$ & 0.0 \\
\hline Region 11 & 769 & 130 & 899 & 4.2 & $116,589.34$ & 0.7 \\
\hline Region 12 & 480 & 190 & 670 & 3.1 & 280.88 & 0.0 \\
\hline Total & 17011 & 4420 & 21431 & 100.0 & $17,712,345.37$ & 100.00 \\
\hline
\end{tabular}

Table 2: THWs Composition and Type, 2014

\begin{tabular}{|c|c|c|}
\hline Composition of Waste & $\begin{array}{l}\text { Volume } \\
\text { generated }\end{array}$ & $\begin{array}{l}\% \\
\text { Share }\end{array}$ \\
\hline Waste with Cyanide & $190,714.45$ & 1.08 \\
\hline Acid Wastes & $5,414.77$ & 0.03 \\
\hline Alkali Wastes & $16,083,724.12$ & 90.81 \\
\hline $\begin{array}{l}\text { Wastes with Inorganic } \\
\text { Chemicals }\end{array}$ & $806,175.49$ & 4.55 \\
\hline Reactive Chemical Wastes & 62.98 & 0.00 \\
\hline Inks/Dyes/Paint/Resins & $134,834.29$ & 0.76 \\
\hline Waste with Organic Solvents & $27,969.08$ & 0.16 \\
\hline Organic Wastes & 352.79 & 0.00 \\
\hline Waste Oil & $124,049.29$ & 0.70 \\
\hline Contaminated Containers & $13,254.72$ & 0.07 \\
\hline Stabilised Wastes & $4,629.12$ & 0.03 \\
\hline Organic Chemicals & $2,263.68$ & 0.01 \\
\hline Miscellaneous Wastes & $318,900.21$ & 1.80 \\
\hline TOTAL & $17,712,345.00$ & 100.00 \\
\hline
\end{tabular}

The data also revealed that out of the total registered THW transporters/haulers of 195 in the country, Region 4A has 60 and zero in Region 4B. NCR has 56 registrants while Region 3 has 34 registrants. In terms of registered treatmentstorage-disposal (TSD) facilities, there is one facility in Region 4B accredited and recognized by DENR.

Moreover, the existing Philippine regulatory framework encompasses the enforcement and compliance for the proper planning and management of THW, including general performance standards, waste classification and exemptions, waste generators registration, waste haulers/transporters/treaters accreditation, waste transport tracking and recording, storage and labeling, treatment, storage and disposal premises, and import/export requirements. It also covers monitoring and enforcement of violations, fines and penalties as well as litigation and prosecution to ensure effective control and regulation of THWs will take place. Despite these regulatory instruments, THWs management in the country is not moving towards sustainability for several key reasons, namely: (a) lack of awareness and management systems of generators; (b) limited technical and financial capacities of haulers/transporters/treaters; and (c) insufficient and lack of enforcement of environmental laws and regulations (Ex Corporation \& Kokusai, 2001).

Thus, these government policies placed additional burdens on the THWs generators. Because of a lack of available land surface disposal areas and appropriate treatment technologies, they will be forced to dispose of both untreated and treated THWs to waterways or to environmentally sensitive areas, and to municipal sanitary landfills or controlled dump sites. The existing environmental laws do not explicitly provide guidelines on siting or site selection criteria, which means that there is no legal basis on the disposal site selection for THWs. As the worst scenario, waste generators are continually practicing the WHIFFY (we-hide-it-freely-for years) approach - it means that waste generators dump or hide their THWs elsewhere; consequently becoming a threat to human health and the environment.

\subsection{Site Selection and Development of Land Surface}

\section{Waste Disposal Facility}

The Philippine government is facing tremendous pressure from the communities where industrial zones are located, as well as from the industries on how to address the increasing generation of THWs. Generators are more concerned with the final disposal of their wastes after undergoing pretreatment processes; on the other hand, the communities' fear is the health threat and environmental risks from illegal 
dumping of untreated and residual wastes. Therefore, there is a need to develop a land surface disposal infrastructure, as one of the alternative solutions to address the problem. However, a major challenge faced by both the government and the private sector's locating suitable sites for THWs disposal. From the initial stage of development of looking for the best site, up to the final stage of implementing the project, requires a long process of approval. Where the facility will be located is also subject to the scrutiny of the community or individuals.

Site selection is the initial stage and the critical aspect of the land surface waste disposal development it requires proper planning to reduce administrative cost and lower the degree of disapproval from the constituents or even to prevent the project being rejected. Siting is a major part in waste management (Kao, et al, 1997), the most important step in land disposal (Gera, 1988), as well as a challenging and often controversial subject in itself. Apogee Research Inc. (as cited by Soesilo and Wilson, 1995) identifies three factors associated with successful siting: (1) the rate of success for on-site facilities was greater than for commercial facilities; (2) sites proposed on already industrialized land were more acceptable than those on non-industrial areas; and (3) storage, transfer and mobile treatment facilities were easier to site than other types of facilities.

Failure in land disposal site selection is contributed to by lack of financial support, appropriate site selection methodologies and public acceptance. Not-in-my-ownbackyard (NIMBY) syndrome or public opposition is considered a perennial problem that leads to failure in the THWs site selection and implementation. Strong local opposition derives from either an inappropriate or incomplete siting analysis or the public's misunderstanding of the site selection procedure (Kao, et.al, 1997). Therefore, public participation is an integral part (Wentz, 1989) and an essential ingredient during the early stage of planning and prior to the start of the site selection process (BadillaRamos, 2000).

\subsection{Spatial Decision Support System - Geographic}

\section{Information System}

The environmental sector started the earliest application of GIS focused on the land use planning, and it is widely used nowadays for intensive numerical and statistical analysis (Longley et al., 2001) in design and planning problems which involve multiple objectives and criteria such as waste management.

As cited by Orban-Ferauge (2011), GIS helps in formulating scenarios for the future due to their ability of visualizing, integrating, analyzing, and modeling giant databases associated with spatial references - also known as "georeferencing". Indeed, GIS is very powerful in connecting information in formulating scenarios. Longley et al., (2001) presented a huge range of GIS applications - utilities, education, banking and finance, market analysis, and military. This application is within the four major areas of concern: local government, business, logistics and environment. GIS also serves as a powerful analytic and decision-making tool for management in testing consequences of development (Yi et al., 2003), and other environmental studies such as air or water quality analysis, disaster management, oil spills and remedial actions, hazard mitigations, forest fires management, etc. Eventually, the emerging popularity of GIS in infrastructure planning and management is also increasing.

Past undertakings in waste disposal facility site selection using various spatial decision support systems and models in a GIS environment vary depending on the availability of spatial digitized data needed to facilitate the GIS application in siting process (Badilla-Ramos, 2000). The spatial data required for the GIS to work are derived from the list of site selection or screening criteria translated from existing digitized base maps into thematic maps employed in the land suitability assessment analysis. Previous studies used a diverse range of siting criteria, most of which are based from existing regulations, studies (Siddiqui et al., 1996) and literature incorporating the spatial, social, economic, political and ecological dimensions of the problem (Kao et al,, 1996). Likewise, previous methods use GIS capabilities only for screening out unsuitable or undesirable sites (Siddiqui et al., 1996). Therefore, the establishment and validation of these sets of criteria using computerized techniques make the decision making process faster, efficient, cost effective, and realistic.

The identification and importance ranking of the site selection criteria is an initial requirement stage of the siting process which involves inputs from the major stakeholders (i.e. waste generators, community organizations, individuals, decision makers, politicians, waste treaters/haulers, etc.). But most often the preferred criteria commonly used in GIS analysis are based on an individual's or expert's judgment, not from consultative, participatory and collective efforts of the major stakeholders in the community. The consultative approach in the establishment of the site selection criteria is relevant and timely to the existing situation of the Philippines, wherein there are no standardized guidelines in the site selection for land surface disposal facility development. The objective of this part of the study is to define, establish and assess the procedural requirements of GIS techniques using the proposed sets of siting criteria and available spatial data in the country. The results will be the basis for developing a workable disposal site selection framework maximizing the benefits derived from computerbased spatial support systems like GIS. It is not part of the study to produce suitability maps as a result of the GIS application, but rather, to assess the viability of suitability techniques vis-à-vis available datasets in the country.

\subsection{Land Suitability Assessment Analysis in GIS}

\section{Environment}

One of the important considerations in land use planning is the allocation of the land for its optimal use. In other words, land is allocated for the purpose for which it is most suited 
(Apan, 1996) or potentially capable of such use. Proper designation of land use reduces the negative impacts of such use to the environment. The need for sound and effective evaluation in land suitability assessment for THWs disposal facility site selection is necessary to minimize the NIMBY (not-in-my-backyard) attitudes among the major stakeholders. Proper assessment will also reduce any potential problems with regards to the technical requirements for such infrastructure development. Due to limited funds and resources, it is important to have a clearer framework for choosing the most suitable sites. This necessitates considerable amount of information to support such siting.

Site selection is considered as a spatial problem which involves large volume of data that can be stored, analyzed and displayed in a GIS environment (Basnet et al., 2001). In addition, the evaluation process does not only include the environmental, biophysical, and political attributes of the land resource, but it also includes the social factors dealing with spatially related information.

Currently, GIS is able to select, rank and map sites that are suitable or unsuitable for a specific purpose (Basnet et al., 2001; Davis, 1996). Overall, land suitability assessment for site selection can benefit from the application of GIS in terms of: (a) capturing, storing, and managing spatially referenced data, (b) providing and performing analysis of massive amounts of spatial data, (c) performing sensitivity and optimization analysis, and (d) communicating model results (Vatalis \& Manoliadis, 2002; Kao, 1997). Thus, GIS becomes powerful for gaining consensus before decisionmaking (Apan, 1996).

As cited by Biermann (1999), land suitability assessment is an essential aspect of land identification process to quantify the potential and constraints factors of developing the lands; and evaluates and prioritizes the available lands based on those identified factors. Land suitability evaluation is also involves land identification for future use patterns, and the economic and environmental feasibility of its current use. There are four major stages of the land suitability assessment, namely: (1) criteria identification and selection, (2) criteria quantification and standardization, (3) criteria weighing and summation, and (4) criteria overlay. These stages of assessment are being integrated to other multicriteria spatial decision support systems such as Analytic Hierarchy Process (AHP) and GIS.

\section{OBJECTIVES}

The main goal of the study is to establish a site selection criteria system in locating feasible land surface disposal areas in the Philippines and be able to implement this system using computer-based support systems like GIS. Specifically, the study also discusses the current problems and issues in managing THWs in the country; establishes a set of screening or siting criteria through a participatory approach; and recommends a workable spatial support planning framework or procedure in THWs land surface disposal site selection for GIS application.

\section{METHODOLOGY}

A qualitative type of research was adopted to successfully meet the objectives of the study. The research methodology covered the review of relevant studies, conduct of actual interviews and surveys, as well as site inspection of existing land surface disposal facilities in the country.

A survey was conducted mainly in Metro Manila, its neighboring provinces and CALABARZON (CaviteLaguna-Batangas-Rizal-Quezon) area. In total, sixty-seven (67) respondents and grouped into three major respondents using a structured questionnaire. These groups include (a) primary-generators group - industries and companies primarily generate and are sources of THW, (b) secondarygenerators group - industrial park/estate and hauling/treating facilities, and (c) non-generators group - private individuals, as well as professional and community organizations. The target groups of respondents were identified based on the author's knowledge that these groups are the main players in THWs management as well as from the past studies. The set of questionnaires or survey forms mainly covered the identification of the level of awareness of the target groups of respondents with regard to their current practices in managing THWs, issues and problems in final disposal of the untreated and treated THWs. The significant part of the survey was the identification and ranking of the set of screening criteria in terms of applicability, relevance and importance to the disposal site selection process.

A three-level site selection or screening criteria system was proposed based from the results of the survey and validated during the consultation process. Consequently, a two-level multi-criteria decision support framework was designed to facilitate the assessment of the land's level of availability and suitability to be developed into acceptable THWs disposal sites. This conceptual analytical model is a procedural framework on how to undertake the land suitability assessment integrated with multi-criteria evaluation such as ranking weighing techniques, Pairwise comparison (AHP), and GIS (map overlay using weighted linear modeling).

\section{RESULTS AND DISCUSSIONS}

\subsection{The Three-Level Disposal Site Criteria/Screening System}

The proposed Three-Level Disposal Site Criteria/Screening System was adapted from Cahill and Holman (Ramos, 2005). In the new proposed system, the criteria for each level were modified and expanded, incorporating additional information from the existing literature in terms of degree of applicability, importance and relevance to the disposal selection process in the country. In addition, the importance rankings of each criterion derived from the results of the survey participated by three major groups of respondents or stakeholders were included in the proposed system.

The proposed site selection system consists of three levels of siting or screening criteria. The Level I criteria - 
"exclusionary criteria" exclude or eliminate sensitive or environmentally critical areas such as: areas with hydrologically and geologically sensitive characteristics, areas subject to flooding and erosion, and other areas that make a valuable contribution towards land conservation and preservation. The Level II criteria - "inclusionary-preferred criteria" include or contain favorable areas/sites such as: present location of THW generators, haulers, and treaters; existing and proposed municipal landfill sites and controlled dump sites, as well as proposed radioactive depositories; proximity to major transportation network; existing industrial zones; location of contaminated sites and abandoned mining sites. Finally, the Level III criteria or the "site-specific criteria" investigate both favorable and unfavorable characteristics of the sites/areas that have passed the previous two levels. This covers hydrogeology characteristics, climatic condition, biological and ecological consideration, economic and social aspects and the overall physical development plan of the area.

The results of the study suggested that the three major groups of respondents have a high awareness of the adverse externalities of poor disposal of THW to the natural environment particularly on water quality, which will have high social and economic costs in the future. The final ranking of selection criteria for each level is summarized in Table 3.

Table 3: The Three Level Disposal Site Selection / Screening Criteria System

\section{Level I. EXCLUSIONARY CRITERIA}

1. Hydrological Characteristics - wetlands, source of freshwater aquifer and critical areas and water supply, watershed areas;

2. Other Environmentally Sensitive Areas - natural and historical landmark, watershed reserved area, agricultural area, protected and natural forests and parks, tourism development area, and other sensitive areas identified by existing laws;

3. Flooding and Erosion Conditions - coastal flood hazard area, cyclonic area, landslide prone area, and other floodplain and storm surge areas; and

4. Geological Characteristics - volcanic and lahar risk zone, seismic risk and impact zone, earthquake fault line, unstable terrain due to mining activity and abandoned oil and gas wells.

\section{Level II . INCLUSIONARY CRITERIA}

1. Location of Existing Treatment, Storage and Disposal (TSD) Facilities - accessibility to THW materials, and existing location haulers/transporters/treaters/recyclers;

2. Location of existing and proposed municipal landfill sites - present and propose disposal sites for identified sites for municipal solid waste either sanitary landfill or controlled open dump sites;

3. Transportation Network - accessibility to major arterial transport networks both land and water;

4. Land Use and Ownership - land use designated for industrial purposes or development government-owned or public lands; and
5. Other Criteria - location of proposed radioactive repository sites, proximity to sources of THWs, location of identified contaminated sites, location of existing and abandoned mining sites.

\section{Level III. SITE-SPECIFIC CRITERIA}

1. Hydrogeology - surface water characteristics, groundwater characteristics, geological condition, soil condition and structure, soil erosion and deposition;

2. Biological Consideration - critical habitat; scenic and recreational area, farmland preservation area, marine life preservation, other sensitive vegetation;

3. Social Consideration - community benefits, population density, health profile, availability of services and utilities, and other demographic data such income, employment;

4. Climatic Condition - air quality, wind direction/patterns, noise and odour levels;

5. Economic Consideration - land property value, land ownership/tenure, site development cost, site life and size, compensation arrangement for affected communities; and

6. Other Criteria - transportation network, comprehensive physical development plan, ecological consideration, and archaeological significance.

\subsection{Conceptual Analytical Framework: A Two-}

\section{Level Multi-criteria Decision Support System}

A conceptual analytical framework is designed to facilitate the assessment of the lands' level of availability and suitability to be developed into acceptable THWs disposal sites as shown in Figure 1. This model is a procedural framework on how to undertake the land suitability assessment integrated with Multi-criteria evaluation and GIS processes. Multi-criteria evaluation and GIS are considered powerful in the process of assessing the suitability of land (Biermann, 1999). Thus, the model illustrates the integration of multi-criteria evaluation using ranking weighing techniques, Pairwise comparison (AHP), and GIS (map overlay using weighted linear modeling). A simple "ranking technique" is applied to determine the importance level of the individual criterion in each siting level. The resulting rankings are subjected to Pairwise comparison technique using the AHP method for further validation based on the author's judgment.

The Three-Level Site Selection/Screening Criteria System provides the primary identification of the selection of factors and data acquisition for this part of the study. Based from the secondary sources, it showed the unavailability of the datasets in digital format is a problem. Only selected local government units' administrative boundaries have been converted into digital form and mostly in paper format. Few of these available maps are relatively recent. Furthermore, relevant data layers (themes) need to be in a digitized format. In this case, most of the available datasets required in this study require manual digitizing using available software in the market to produce vector coverages. 


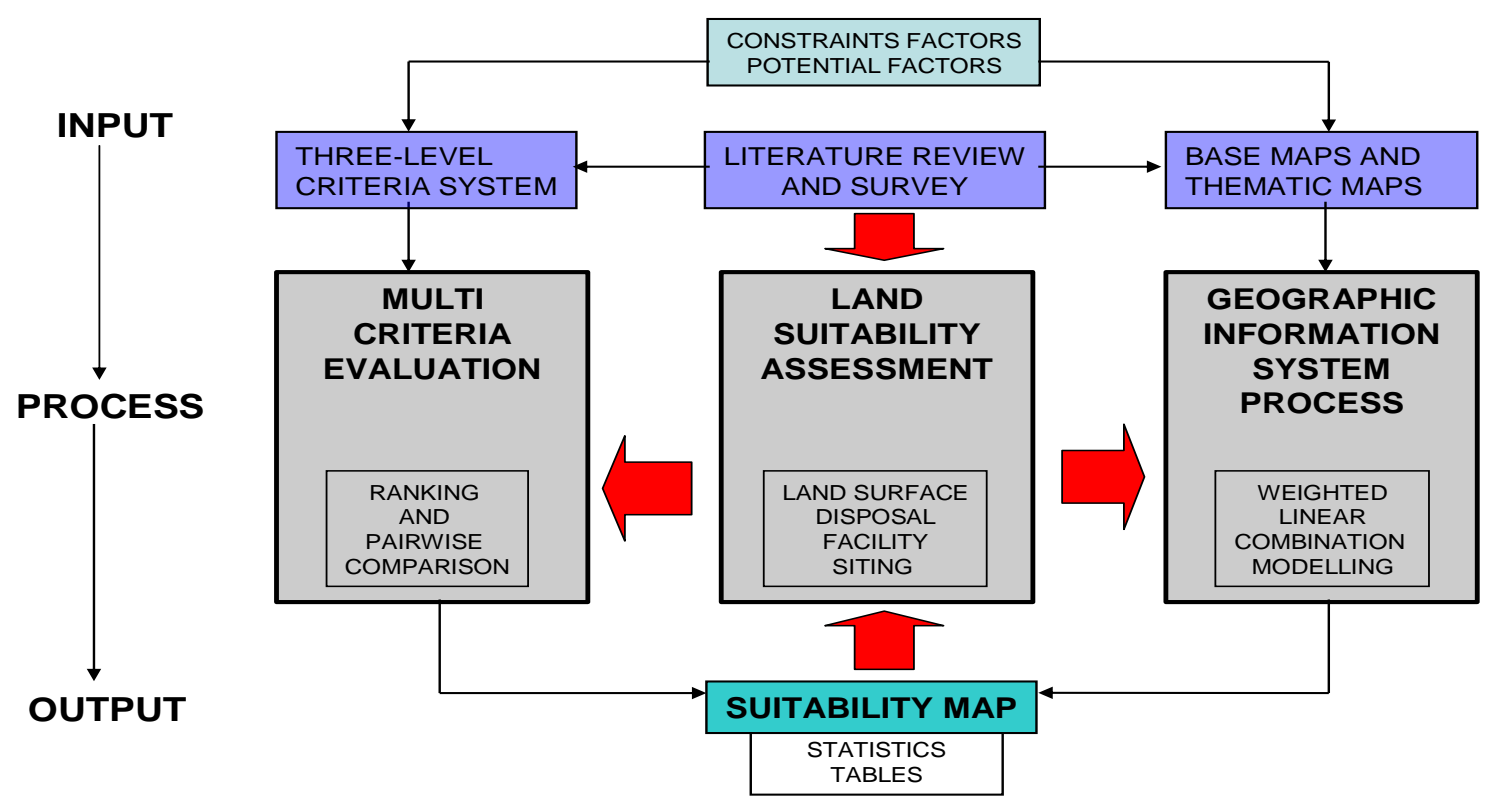

Figure 1: Conceptual Analytical Spatial Decision Support Framework

According to Basnet et al. (2001), most of the previous studies involved a vector-based method to identify landfill sites in the United States, dumpsites in Malaysia, municipal waste disposal sites in the Philippines, and animal waste application in Australia. However, in this study a rasterbased method will be employed for reasons stated by Eastman, et al. (1993) as follows: (a) it has more analytical power in the analysis of continuous space; (b) it is ideally suited to the study of data that are continuously changing over space such as terrain, vegetation biomass, rainfall, etc.; (c) its structure closely matches with the architecture of digital computers; and (d) it tends to be rapid in the evaluation of problems that involve various mathematical combinations of the data in multiple grids.

After applying appropriate digitizing techniques to avoid generation and propagation of errors, topology creation and geo-referencing are executed, followed by conversion of the vector coverages into raster-based data (Apan, 1996).

\subsection{Data Analysis: Multi-criteria Evaluation and}

\section{GIS Operation}

The data analysis involves two major stages: multi-criteria evaluation using the Pairwise comparison technique and the criteria (factors) overlay using the weighted linear modelling in a GIS environment. The accuracy of the results of the analysis is dependent on the available datasets for constraint factors and potential factors represented in thematic layers. Moreover, the assessment of the relative ranking and scoring for each factor using the Pairwise comparison affects the outcome of the suitability analysis (Apan, 1996).

A multi-criteria evaluation (MCE) is a decision making tool which defines objectives, formulate criteria and evaluate solutions based upon spatial properties and preferences (Pullar, 1999). One of the important steps in the MCE approach is the articulation by decision makers (i.e. stakeholders) of the varying importance (preference) they give relative to the criteria. The preference is an expression of stakeholder's values, and in the MCE perspective it is the varying degrees of importance assigned to criteria. Criterion Weighing Techniques are the common methods to illustrate those multi-criteria that have varying importance. Each criterion is assigned a numeric value - weight that indicates its importance relative to other criteria in the decision situation. The weights are normalized so that the sum of all the criteria under consideration equals to 1 . Under these techniques, two methods are employed in the study to assess the importance rating of the criteria under consideration. The results in the establishment of the Three-level site Selection/Screening Criteria System will be subjected to Ranking Method and Pairwise Comparison.

AHP is used to derive the weights of each criterion which employs a Pairwise comparison procedure to come up with a scale of preference sets of criteria and gives a measure of consistency of judgments applied in deriving the weight for each criterion and factor (Apan, 1996). AHP has been applied in various settings with complex decision problems (Siddiqui, et al., 1996). As noted by Siddiqui et al. (1996), AHP is applied in landfill siting studies, health care, space exploration, urban planning, and politics. AHP can be applied using IDRISI's built-in function (Basnet, et al., 2001) or can be done manually using the following mathematical formulas and sequence of steps (Yi, et al., 2003; Apan, 1996). Due to limited datasets for IDRISI's application, the manual computation presented here is only a preliminary assessment and validation of the siting criteria ranked by the major stakeholders. The tabulated weights for each criterion and the factors under each criterion are determined and interpreted by the author using the nine point rating scale (Davis, 2002; Apan, 1996), where from 1 $=$ relative to the column variable, the row variable is equally important, and to $9=$ relative to the column variable, the row variable is absolutely more important. 
To illustrate this with exclusionary criteria as shown in Table 4, row A variable which is criterion 1 is compared to column A variable (criterion 1), the weight assigned is 1 which means that criterion 1 compared to the same criterion is equally important. On the other hand, row $\mathrm{A}$ variable (criterion 1) has a weight of 5 in relation to the column B variable (criterion 2), which means that criterion 1 is more important or five times important than criterion 2. This means that criterion 1 is important than criteria 2,3 and 4 in varying level of importance based on the established rating scale. Another scenario of comparison is demonstrated between criterion 2 (row B variable) and criterion 1 (column A variable). The assigned weight for criterion 2 is $1 / 5$ which only means that this criterion (column B variable), is relatively five times less important that the criterion 1 (column A variable).

Table 4: Tabulated Weights using Pairwise Comparison Method

\begin{tabular}{|c|c|c|c|c|c|c|c|c|}
\hline & $\begin{array}{l}\text { Exclusionary } \\
\text { Criteria }\end{array}$ & A & $\mathrm{B}$ & $\mathrm{C}$ & $\mathrm{D}$ & $\begin{array}{l}\text { AVE } \\
\text { RANK }\end{array}$ & RANKING & WT \\
\hline A & Criteria 1 & 1 & 5 & 7 & 9 & 1.23 & 1 & 0.1 \\
\hline B & Criteria 2 & $1 / 5$ & 1 & 3 & 5 & 1.42 & 2 & 0.2 \\
\hline $\mathrm{C}$ & Criteria 3 & $1 / 7$ & $1 / 5$ & 1 & 3 & 1.52 & 3 & 0.3 \\
\hline \multirow[t]{2}{*}{$\mathrm{D}$} & Criteria 4 & $1 / 9$ & $1 / 7$ & $1 / 3$ & 1 & 1.66 & 4 & 0.4 \\
\hline & Total & 1.45 & 6.34 & 11.33 & 18.00 & & TOTAL & 1.0 \\
\hline
\end{tabular}

\begin{tabular}{|l|l|c|c|c|c|c|c|}
\hline & & $\mathrm{A}$ & $\mathrm{B}$ & $\mathrm{C}$ & $\mathrm{D}$ & $\begin{array}{c}\text { Row } \\
\text { total }\end{array}$ & $\begin{array}{c}\text { Row } \\
\text { average }\end{array}$ \\
\hline A & Criteria 1 & & & & & & \\
\hline B & Criteria 2 & 0.69 & 0.79 & 0.62 & 0.50 & 2.59 & $\mathbf{0 . 6 5}$ \\
\hline C & Criteria 3 & 0.10 & 0.03 & 0.09 & 0.17 & 0.38 & $\mathbf{0 . 1 0}$ \\
\hline D & Criteria 4 & 0.08 & 0.02 & 0.03 & 0.06 & 0.18 & $\mathbf{0 . 0 5}$ \\
\hline
\end{tabular}

Next steps are for calculating consistency of the ranking

\begin{tabular}{|c|c|c|c|c|c|c|}
\hline & Row average & 0.65 & 0.21 & 0.10 & 0.05 & \multirow[b]{2}{*}{$\begin{array}{c}\text { Vector } \\
\text { C }\end{array}$} \\
\hline & & & & & & \\
\hline A & & 0.65 & 1.05 & 0.67 & 0.41 & 2.78 \\
\hline $\mathrm{B}$ & & 0.13 & 0.21 & 0.29 & 0.23 & 0.86 \\
\hline $\mathrm{C}$ & & 0.09 & 0.04 & 0.10 & 0.14 & 0.37 \\
\hline $\mathrm{D}$ & & 0.07 & 0.03 & 0.03 & 0.05 & 0.18 \\
\hline
\end{tabular}

consistency index $(\mathrm{CI})=$

$\mathrm{N}$

RI

For calculation of $\mathrm{RI}=0.90$,

the consistency ratio (C.R.) $=$
0.01

$\begin{array}{llll}1.00 & 2.00 \quad 3.00 & 4.00\end{array}$

$\begin{array}{llll}0.00 & 0.00 & 0.58 & 0.90\end{array}$

8.00
1.41

WT

0.2

1.0

0.01

After assigning weights for each criterion or factor, the weights are added to determine the total weights and for calculating the priority weights. The priority weights for each different factor or criterion are determined by dividing each individual assigned weight with the total weights (computed from the first matrix). Row total weights are computed from the sum of the priority weights for all different criteria or factors (in columns). Each row average weight (vector B) is calculated by dividing the row total

weights by the total number of factors or criteria used and multiply with 100 as normalization of $100 \%$.

To determine the consistency of ranking, each row weight from the paired comparison from the first matrix are multiplied by the principal vector or priority weights (row average) to get the new vector (vector $\mathrm{C}$ ). The average vector $C$ is the sum of the entire individual new vector for each criterion or factor. Each average vector $C$ is divided by its corresponding row average weight (vector B) to calculate 
the new vector $D$. The average weight for the calculated new vector $\mathrm{D}$ is called the maximum eigen value "lamda max". This value will be utilized in the determining the consistency index $(\mathrm{CI})$, subsequently for the calculation of random index $(\mathrm{RI})$ and consistency ratio $(\mathrm{CR})$.

The results show that the author's judgment towards the respondents' ranking for all levels criteria is acceptable. The consistency ratios are within the consistency ratio (CR) based on Saaty's (1990) empirical suggestion of 0.10 which is acceptable. Smaller results are more consistent in Pairwise comparison.

\subsection{GIS Process}

The role of GIS is to facilitate the mapping and calculation of the degree of suitability and availability of sites that are potentially capable to be developed into land disposal areas. The calculation is based on the sets of criteria discussed earlier using the weighted linear combination model. GIS also provide the analysis of both spatial and attribute data using ArcView, ARC/INFO programs or IDRISI.

At this stage of the suitability analysis, all the constraints and potential factors are already translated into thematic maps. For Level I: Exclusionary Criteria (Constraint Factors), it is recommended that a map scale of 1:250,000 for this level can be applied. It means that all the constraint factors will be screened in a 1:250,000 scale digitized map. This screening approach reduces the volume of data to be processed for further GIS operation. Level II: Inclusionary Criteria (Potential Factors) will be done either in a 1:100,000 or 1:75,000 map scale, and Level III: SiteSpecific Criteria will be subjected to a 1:50,000 map scale.

The site suitability level is determined by calculating the suitability index (SI). SI for each cell or grid is determined by aggregating relative importance weights (RIWs) at each level of the criteria or factors hierarchy (Siddiqui et al., 1996). RIWs are the values of the weights derived from the Pairwise comparison (AHP technique). Within GIS application, SIs for all raster cells are determined simultaneously using map algebra function. The higher the suitability number for a given cell, the more suited the raster cell is to be selected as a potential site for disposal (Siddiqui, et al., 1996). The SI can be also classified into areas of high, medium, and low suitability within the GIS software function (Basnet et al, 2001). As cited by Basnet et al (2001), this method identifies natural breakpoints by looking for groupings and patterns inherent in the data. The writer added that coefficient of variation, weighted standard deviation, and weight averages of SIs are computed to have full understanding of the overall degree of suitability.

\section{CONCLUSIONS}

This paper aimed to develop and establish a set of site selection or screening criteria which could be proposed towards improvement in the current disposal siting practices in the Philippines. In spite of government policies on THWs management, problems and issues have persisted due to the lack of standard criteria for siting as well as an institutionalized site selection process.

The lack of a centralised land surface facility for THWs has aggravated the situation. The dynamic pace of industrialization and urbanization in the country lends itself to the need for proper site selection and allocation of land for the construction of a disposal facility. This would be an important indicator for environmental sustainability. Presumably, land scarcity was not an issue in the establishment of a centralized disposal facility; the problem lies much more in the absence of a standardized site selection or screening mechanism. It is also important to gain public support in disposal site selection and development.

The Three-Level Site Criteria System developed in this study would significantly contribute to the improvement of the site selection or screening practices in the country. Broadly, it could be utilized in three ways. First, the proposed system could used to validate the existing criteria employed by most Consultants. Second, the adoption of the conceptual analytical framework validation using a computer-based spatial support system such as the Geographic Information System (GIS) influence the standardisation of criteria site selection mechanisms, particularly it will improve the present "ad-hoc" approach for the site selection of the land surface disposal facility in the country. Thus, integration of this framework with other existing planning and management tools such as land use planning, environmental impact assessment, and strategic planning will bring a holistic approach of disposal site selection and development.

\section{REFERENCES}

[1] Apan, A. (1996) Land Resource Survey and Evaluation for Tropical Forest Rehabilitation: Approaches Using Satellite Imagery and GIS. Thesis submitted in the Department of Geography and Environmentl Science, Monash University, Australia.

[2] Badilla-Ramos A. (2000) Draft Report. Part 1 and 2. Development of a Computer-Aided Tool for siting Sanitary Landfills (CATSSAL) in the Philippines, Ph.D. Thesis, Griffith University, Brisbane, Australia.

[3] Basnet, B., Apan, A., Raine, S. (2002) Geographic Information System based Manure Application Plan. Journal of Environmental Management, 64 99-113.

[4] Biermann, S. (1999) The Strategic Identification of Suitable Land for Low Income Housing: A Case Study from South Africa, Spatial Multicriteria Decision Making and Analysis. Jean-Claude Thill (eds), Ashgate Publishing Ltd, England.

[5] Cahill L.B. and Holman W.R. (1981) Siting Waste Management Facilities. Hazardous Waste Management, Ann Arbor Science Publishers, pp.86-97.

[6] Davis, B. (1996) GIS A Visual Approach. On Word Press, Santa Fe, USA.

[7] Department of Environment and Natural Resources (1995) Orientation Manual for the Implementing Rules and Regulations for Title II. The Management of 
Chemicals and Toxic Substances, DENR Administrative Order.29, Republic Act 6969, EMB, Manila.

[8] Department of Environment and Natural Resources (1995) Orientation Manual for the Implementing Rules and Regulations for Title III. The Management of Hazardous Waste, DENR Administrative Order.29, Republic Act 6969, EMB, Manila.

[9] Entec Europe Ltd., ECOTEC Research and Consulting Ltd, and Dames and Moore (1996) Toxic and Hazardous Waste Management Project, Metro Manila, Philippines.

[10] Environmental Management Bureau (2015) Regional Distribution of Hazardous Waste Generation Amount by Type of Hazardous Waste, Environmental Quality Division - Hazardous Waste Management Section, DENR, Quezon City.

[11] Eastman, R., Kyem, A., Toledano, J., Weigen, J. (1993) GIS and Decision Making: Explorations in Geographic Information Systems Technology, UNITAR, Geneva.

[12] Ex Corporation and Kokusai Kogyo Co., Ltd. (2001) Japan International Cooperation Agency (JICA) Final Report. The Study on Hazardous Waste Management in the Republic of the Philippines (Phase 1), Manila.

[13] Gera, F. (1988) Modelling Long Term Impacts of Land Disposal of Hazardous Waste, Land Disposal of Hazardous Waste: Engineering and Environmental Issues, Gronow, J.R. Schofield, A.N., Jain, R.K. (eds.) Ellis Horwood Limited, England.

[14] Kao J., Lin H. and Chen, W (1997) Network Geographic Information System for Landfill Siting. Waste Management and Research, 15, 239-253.

[15] Longley, P., Goodchild, M., Maguire, D., Rhind, D. (2001) Geographic Information Systems and Science, John Wiley and Sons, Ltd., Chichester, England.

[16] Orban-Ferauge, F. (2011) Participatory geographic information systems and land planning: life experiences for people empowerment and community transformation, FUNDP, Namur, Belgium.

[17] Portney, K. (1991) Siting of Hazardous Waste Treatment Facilities. The Nimby Syndrome Auburn House, CT, USA.

[18] Pullar, D. (1999) Using an allocation Model in Multi Criteria Evaluation. Journal of Geographic Information and Decision Analysis, Vol 3, No 2, 9-17.

[19] Ramos, R. (2005) Infrastructure Siting Development for Land Surface Disposal of Toxic and Hazardous Wastes in the Philippines, Mphil Thesis, University of Queensland, Brisbane, Australia.

[20] Ramos, R.P. (2003) Waste Management in Developing Countries. A Case Study of the Toxic and Hazardous Waste in the Philippines, A paper presented and published in the Environmental Research Event (EERE) Conference Proceedings, Mowlaei, Rose and Lamborn (eds), pp305-314, Melbourne, Australia.

[21] Saaty, T.L. (1990) The Analytic Hierarchy Process: Planning, Priority Setting, Resource Allocation, Pittsburg, RWS Pubications.

[22] Siddiqui, M., Everett, J., Veux B. (1996) Landfill Siting Using Geographic Information Systems: A
Demonstration. A Journal of Environmental Engineering, June 1996, 515-523.

[23] Soesilo, A. \& Wilson, S. (1995) Hazardous Waste Planning, CRC Press, Inc., Florida.

[24] United States Environmental Protection Agency (1995) Process Design Manual, Surface Disposal Sewage Sludge and Domestic Septage. US-EPA, Washington, D.C., USA.

[25] U.S. Environmental Protection Agency (1995) Process Design Manual for Surface Disposal of Sewage Sludge and Domestic Septage, USA.

[26] Vatalis, K. \& Manoliadis, O. (2002) A Two-level Multicriteria DSS for Landfill Site Selection Using GIS: A Case Study in Western Macedonia, Greece, Journal of Geographic Information and Decision Analysis, Vol 6, No 1, 49-56.

[27] Wentz, Charles A. (1989) Hazardous Waste Management. McGraw-Hill, Inc., New York.

[28] Yi, D., Lulu, N., Lin, K., \& Diana, S (2003) Application of GIS and Remote Sensing for Assessing Watershed Ponds for Aquaculture Development in Thai Nguyen, Vietnam, Map Asia, Malaysia.

\section{BIOGRAPHIES}

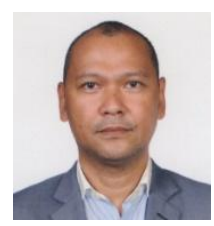

Engr. Ramos is an Associate Professor of the College of Engineering and Technology of the Romblon State University, Philippines. A registered Civil Engineer, Engr. Ramos has a $\mathrm{PhD}$ degree in the Built Environment at the University of Ulster, Northern Ireland, UK. He got MPhil degree in Environmental Engineering at the University of Queensland, Australia. His research area of interests include geographic information system, environmental impact assessment, environmental management system, water quality of river systems, urban regeneration, and green building. 